\title{
Early vertical correction of the deep curve of Spee
}

Renato Parsekian Martins ${ }^{1}$

DOI: http://dx.doi.org/10.1590/2177-6709.22.2.118-125.sar

Even though few technological advancements have occurred in Orthodontics recently, the search for more efficient treatments continues. This paper analyses how to accelerate and improve one of the most arduous phases of orthodontic treatment, i.e., correction of the curve of Spee. The leveling of a deep curve of Spee can happen simultaneously with the alignment phase through a method called Early Vertical Correction (EVC). This technique uses two cantilevers affixed to the initial flexible archwire. This paper describes the force system produced by EVC and how to control its side effects. The EVC can reduce treatment time in malocclusions with deep curves of Spee, by combining two phases of the therapy, which clinicians ordinarily pursue sequentially.

Keywords: Curve of Spee. Biomechanics. Overbite.

Apesar de haver poucos desenvolvimentos tecnológicos nos últimos anos dentro da Ortodontia, a busca por tratamentos mais eficientes não cessou. Assim, o presente artigo visa analisar, de maneira lógica, como otimizar uma das fases do tratamento ortodôntico que mais demandam tempo: a correção da sobremordida exagerada. Pretende-se demonstrar como realizá-la concomitantemente ao alinhamento inicial, por meio de uma técnica denominada correção vertical precoce (CVP). Essa técnica utiliza dois cantilevers associados ao primeiro fio de alinhamento ortodôntico, mas não restritos a ele, a fim de iniciar a planificação da curva de Spee o mais cedo possível. Assim, o tempo de tratamento pode ser diminuído, já que duas fases do tratamento, normalmente realizadas de forma independente, podem ser realizadas ao mesmo tempo. Além disso, tanto o sistema de forças quanto os efeitos colaterais e os passos da execução da técnica serão devidamente apresentados e discutidos.

Palavras-chave: Curva de Spee. Biomecânica. Sobremordida.

${ }^{1}$ Private practice and part-time Faculty, Universidade Estadual Paulista (UNESP), Department of Pediatric Dentistry, School of Dentistry, Araraquara, São Paulo, Brazil. Visiting professor, Jacksonville University School of Orthodontics, Jacksonville, Florida, USA.

Contact address: Renato Parsekian Martins Rua Carlos Gomes 2158, Araraquara/SP - CEP: 14.801340

E-mail: dr_renatopmartins@hotmail.com
How to cite this article: Martins RP. Early vertical correction of the deep curve of Spee. Dental Press J Orthod. 2017 Mar-Apr;22(2):118-25. DOI: http://dx.doi.org/10.1590/2177-6709.22.2.118-125.sar

Submitted: January 26, 2017

Revised and accepted: March 03, 2017

» The author reports no commercial, proprietary or financial interest in the products or companies described in this article.

» Patients displayed in this article previously approved the use of their facial and intraoral photographs. 


\section{INTRODUCTION}

The search for more efficient treatment protocols continues unabated. Although some believe that more therapeutic efficiency implies only in a monetary advantage, it also has a positive correlation with the avoidance of root resorption and periodontal threats. ${ }^{1}$ Therefore, faster treatment offers patients biological advantages.

If patients desire faster therapy, doctors have the responsibility of discovering why the average treatment lasts two years. ${ }^{2}$ The best scientific evidence now available indicates that the type of malocclusion, clinical decisions and patient compliance ${ }^{3-5}$ have more importance than the technique or bracket used. ${ }^{4,6,7}$ Therefore, altering "technique-sensitive" features can hardly improve efficiency or reduce treatment time, unless these features are common to all techniques.

One can divide orthodontic treatment into five phases for evaluating efficiency: alignment, transverse correction, vertical correction (flattening of the curve of Spee), anteroposterior (AP) correction and finishing. Alignment probably requires the least time (Fig 1), thus optimizing it would do little to reduce treatment time. Controlling vertical and AP correction offers clinicians more opportunity to significantly reduce treatment time and increase efficiency.

The literature has shown some strategies that significantly reduce treatment time by managing AP relationships - e.g., extraction of maxillary premolars to treat severe Class II malocclusions ${ }^{8}$-, whereas little information exists regarding how the vertical dimension can influence efficiency. This lack of evidence offers a fertile opportunity for improving and accelerating treatment.

When comparing open and deep bites, the latter offers orthodontist the most challenge because it occurs more often and affects about $20 \%$ of the population, compared to $0.5 \%$ with open bites. ${ }^{9}$ Also, modern orthodontic appliances have a second order low stiffness, which elastic forces cannot assist as they can in open bite corrections. This stiffness deficiency occurs because when Edward Angle changed the design of his early orthodontic appliance from the ribbon arch bracket to the edgewise in $1928,{ }^{10}$ he increased the stiffness in the first order dimension to favor his objective of arch expansion.

Today, other alternatives can create spaces in the transverse and AP directions, e.g., nickel-titanium (NiTi) wires normally used for alignment can also produce expansion forces. ${ }^{11}$ Nonetheless, the problem in leveling the curve of Spee continues and orthodontists often use reverse curve archwires to increase the vertical force needed to correct a deep bite.

The major issue with the contemporary edgewise techniques is that rotations need correction with a resilient archwire, e.g., 0.014-in NiTi (Figs 2A, 2B and 2C) before a heavier archwire is used to flatten the curve of Spee (Figs 2D, 2E and 2F). Total correction of the curve of Spee will only occur with rigid archwires, such as the ones produced with stainless steel or beta-titanium alloys (Fig 2G, 2H, 2I) and not on round or rectangular NiTi archwires. This makes the current orthodontic protocol somewhat inefficient because it requires the correction of a primary problem (aligning) before addressing a secondary problem (leveling). A more efficient protocol would align the teeth and simultaneously level the curve of Spee.

\section{ALTERNATIVES FOR THE CURVE OF SPEE CORRECTION}

One strategy proposed at the end of the $1980 \mathrm{~s}^{12}$ is the addition of a reverse curve in NiTi archwires (Fig 3), which increased deflection and, as a consequence, the vertical force. While this strategy is effective and offers advantages over the conventional "straight archwire" technique, since vertical correction begins with the initial round NiTi archwire or as soon as a rectangular archwire of the same alloy is placed (Fig 4), it has limitations. When stress is applied to a NiTi archwire, it undergoes a martensitic transformation that increases its superelastic features, which exerts less force to the teeth. Also, the increased crown-labial torque the reverse curve exerts on the mandibular incisors when used in it rectangular form often produces undesirable effects. 

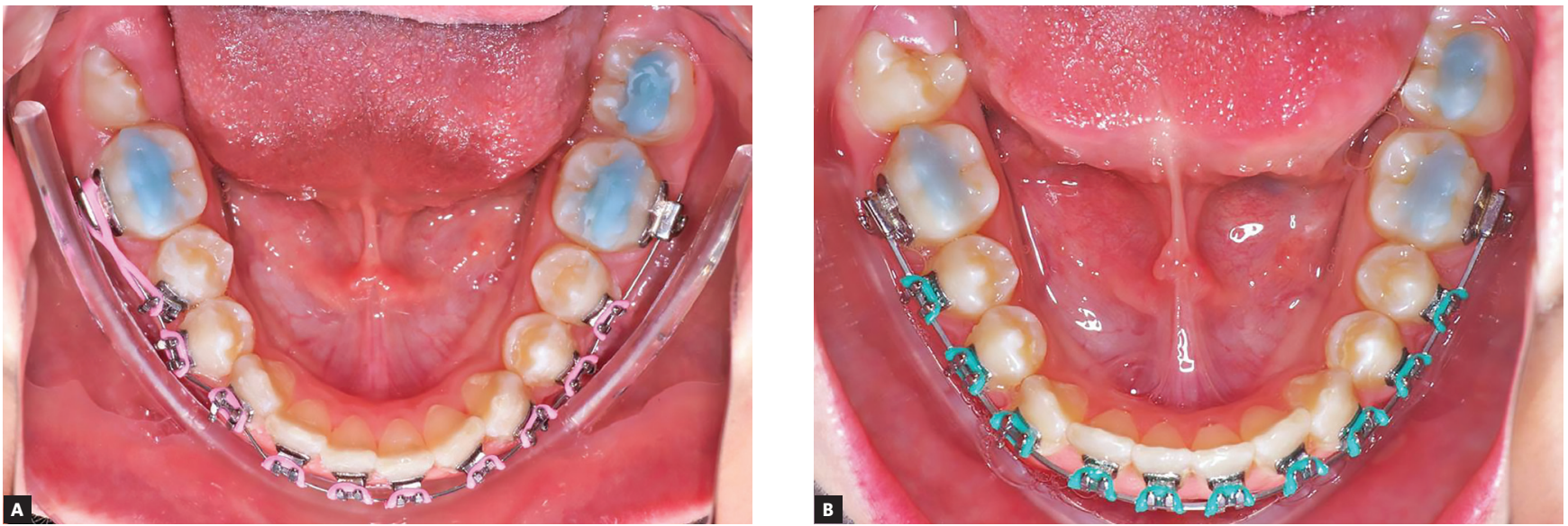

Figure 1 - A) Beginning of the alignment phase with a 0.014-in NiTi archwire. B) After two months of treatment, a 0.016 × 0.022 -in NiTi archwire was placed.
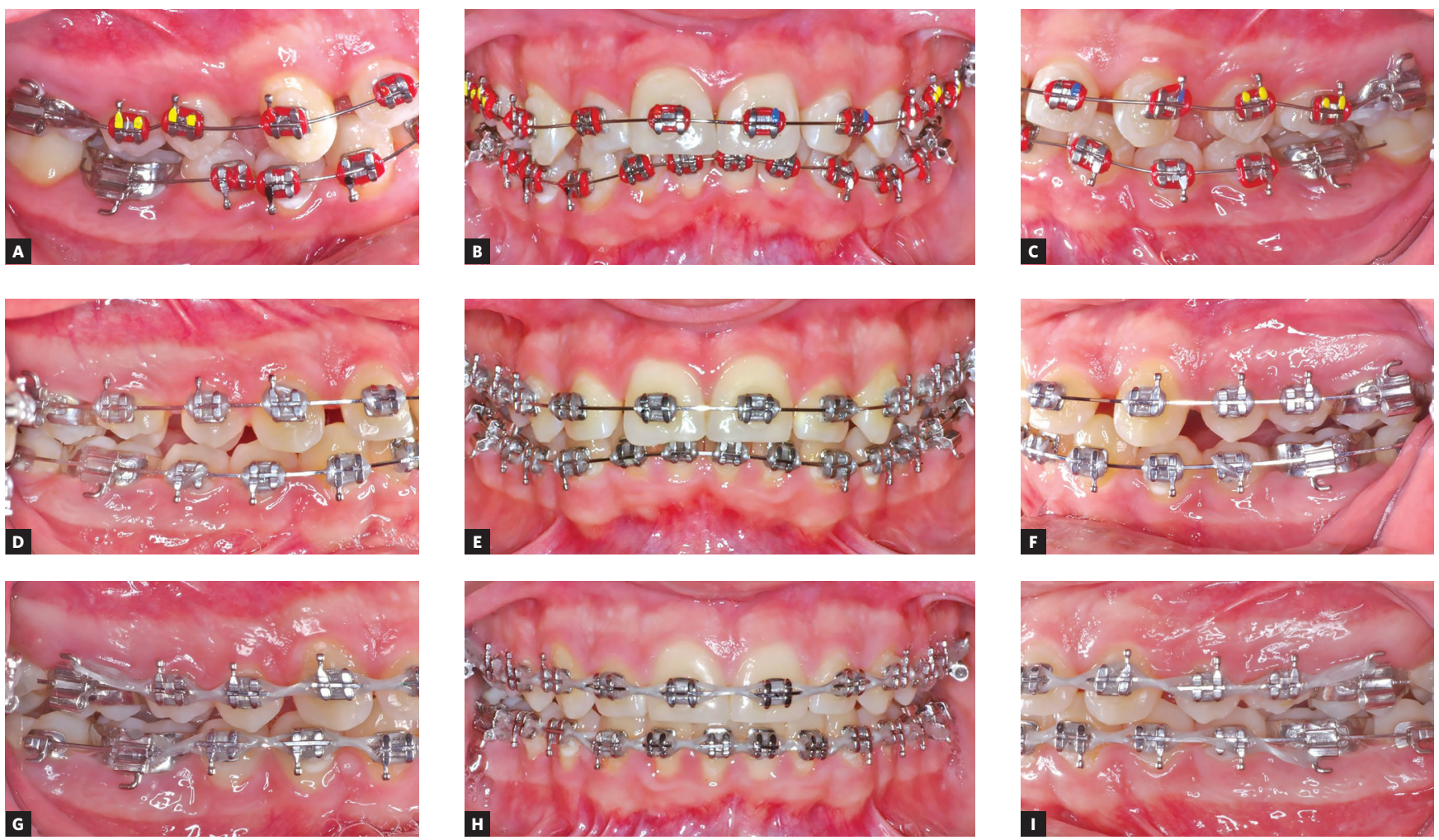

Figure 2 - Conventional treatment of a deep curve of Spee using a contemporary edgewise technique with 0.018-in MBT prescription brackets. A, B, C) 0.014-in NiTi archwires initially placed. D, E, F) Treatment progress after 0.014-in and 0.016 × 0.022-in NiTi archwires were used and replaced by $0.016 \times 0.022$-in stainless steel archwires. The flexible NiTi archwires produced a minimum vertical correction. G, H, I) Treatment progress, with flattened curve of Spee and improved vertical relationship. 
Another solution to the problem of low stiffness can be the use of a more rigid archwire engaged over the flexible alignment wire. In segmented orthodontic techniques such as Bioprogressive or the Segmented Arch Technique, a rectangular base-archwire is inserted into the slot of the anterior brackets or tied over a base archwire, respectively (Figs 5 and 6) for that purpose. However, these auxiliary archwires can also produce unwanted effects such as:

» introduce an indeterminate force system that produces an extrusive force on the incisors rather than an intrusive one; ${ }^{13}$

» the production of excessive distal moments on the molars and proclined incisors when the point of force application is located at the midline over the main archwire;

» the chairside construction of these archwires, which require helices, consume time and inconveniences patients as well as challenges clinicians.

\section{THE EARLY VERTICAL CORRECTION (EVC) OF THE DEEP CURVE OF SPEE}

A better solution to the aligning/vertical problem would be to start the vertical correction early and simultaneously with alignment. A cantilever auxiliary wire can be attached on each side of the mandibular alignment archwire to flatten the curve of Spee while the alignment of teeth occurs (Fig 7). These cantilevers should have their points of force application between the mandibular canines and lateral incisors. This creates an intrusive force near the axis of resistance (AR) of the incisors, which avoids unnecessary proclination and produces a crown-mesial moment on the canine that is usually distally inclined in cases with deep curves of Spee. This decreases the extrusive effect on the incisors caused by the same distal axial position of the canines, because this cantilever deflects the archwire apically (Fig 8). Additionally, the crown-distal moment
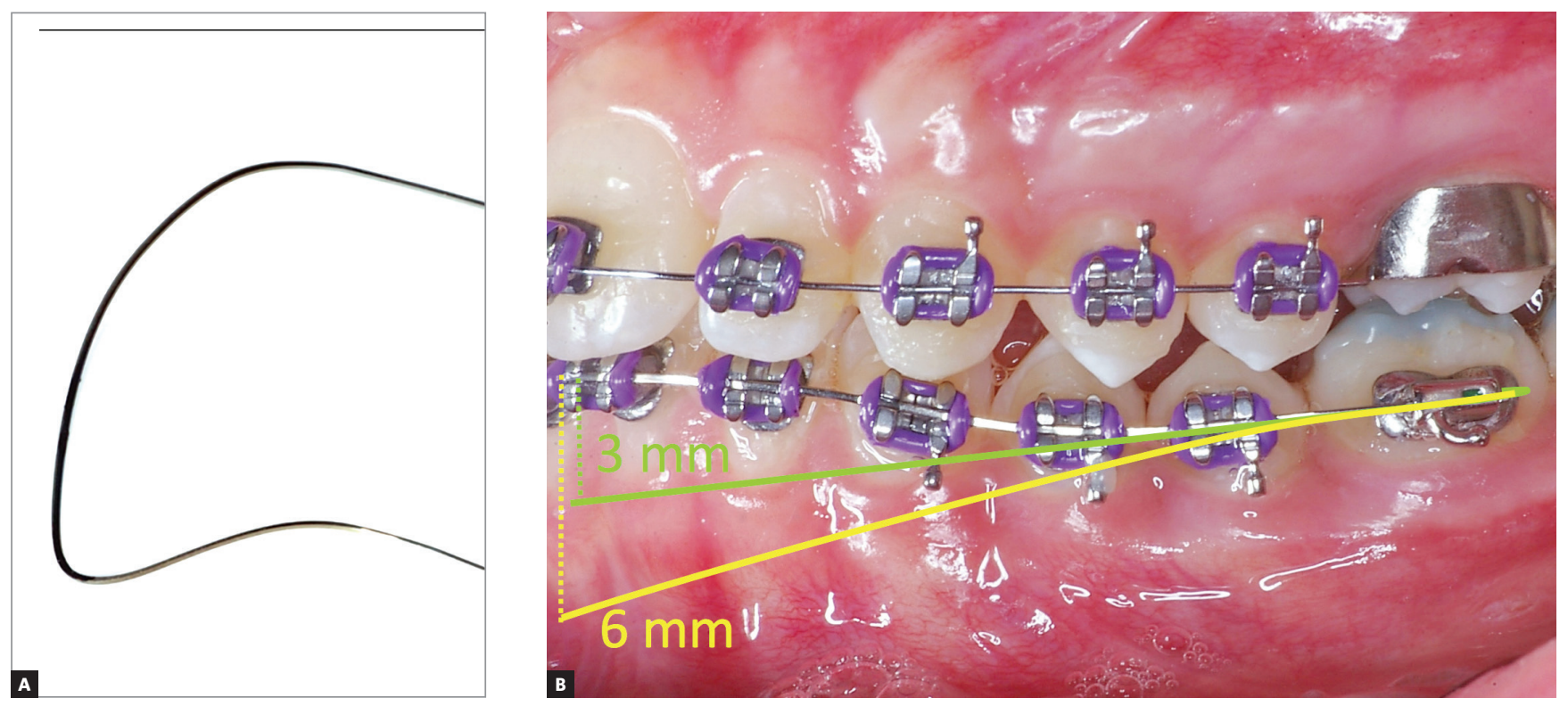

Figure 3 - The rationale of a reverse curve NiTi archwire used for vertical correction. The green line depicts an estimated 3-mm activation when a flat archwire is placed, whereas the yellow line shows the increased vertical activation caused if a reverse curve is placed to the archwire. The reverse curve would produce twice the intrusive force of the flat wire. 

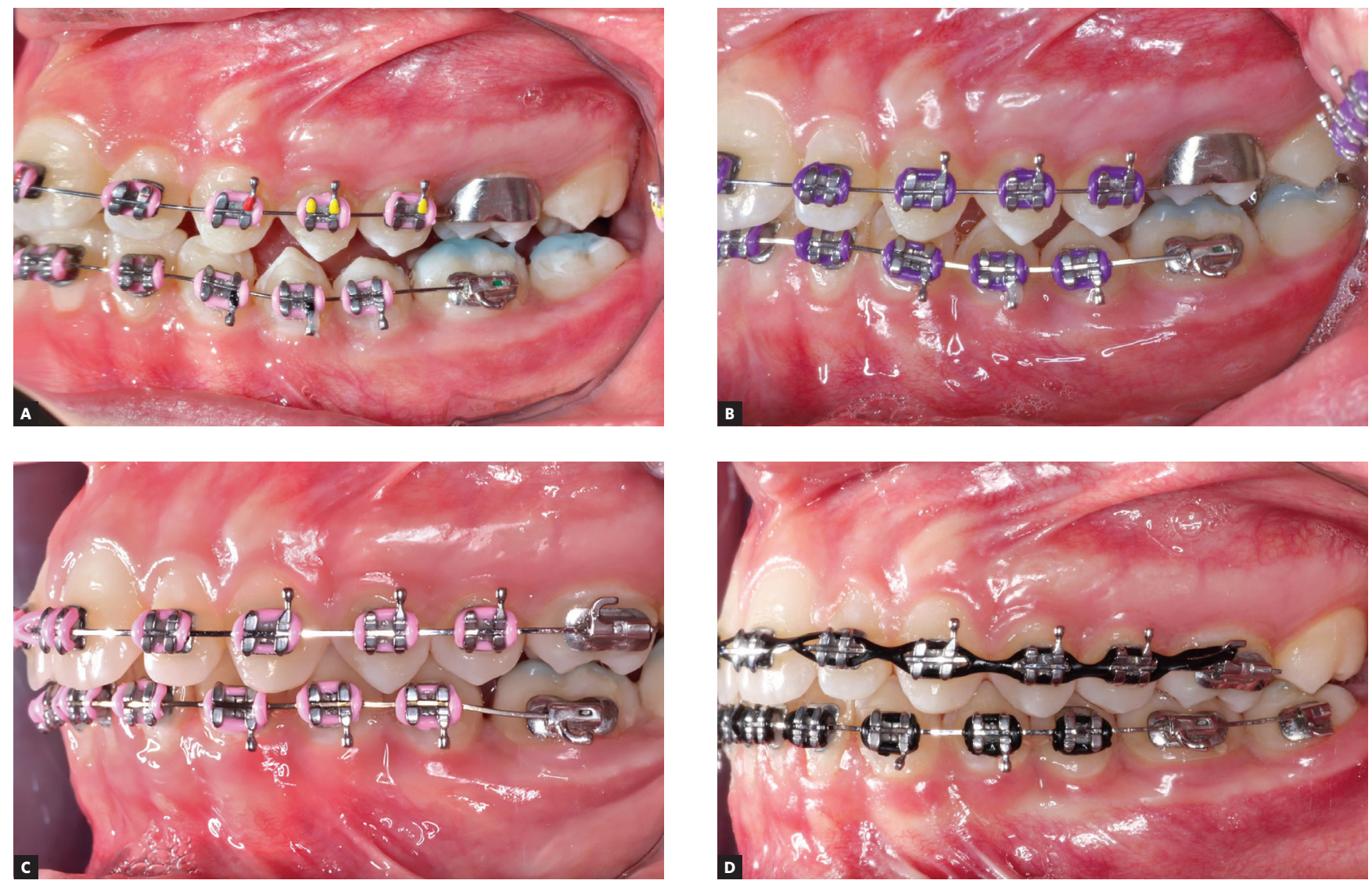

Figure 4 - Treatment of the lower deep curve of Spee with reverse curve NiTi archwires on 0.018-in slot brackets. A) A 0.014-in NiTi archwire with reverse curve is placed along a bite raise to avoid contacts of the lower brackets with the upper teeth. B) After a two-month progress, a $0.016 \times 0.022$-in NiTi archwire with reverse curve is placed. The deflection of the archwire is similar to that of the 0.014-in wire, which was not capable of flattening the curve of Spee. C) After six months of total treatment time, a $0.016 \times 0.022$-in NiTi archwire with reverse curve is tied-in. The curve of Spee and the archwire are flat and the first molars are overcorrected, but the overbite correction is confounded by abrasion of the bite raise. D) After one year of total treatment, the $0.016 \times 0.022$-in stainless steel archwire has almost corrected the curve of Spee.

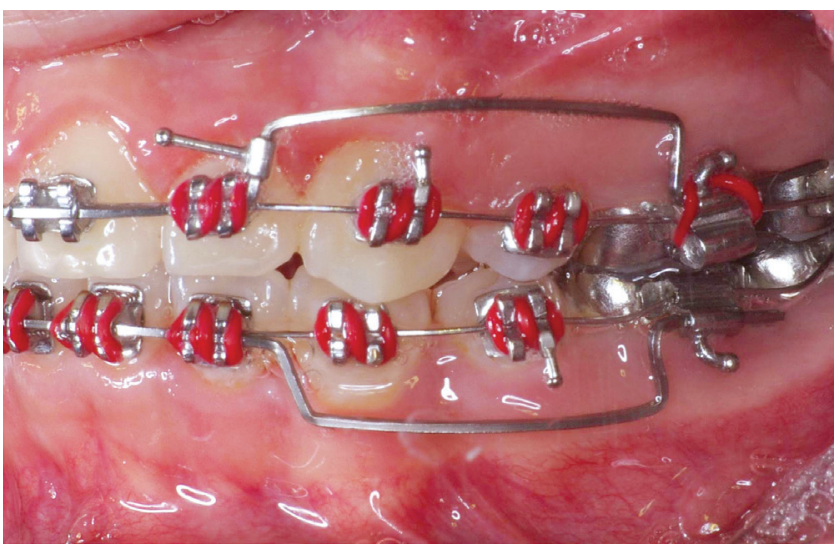

Figure 5 - Two $0.017 \times 0.025$-in beta-titanium intrusion base archwires can be inserted into the slots of the brackets over a flexible archwire to assist leveling. Because the force system in indeterminate, they might not produce intrusion if an incorrect activation is placed, e.g., an anterior bend intending to cause intrusion of the incisors might actually cause extrusion.

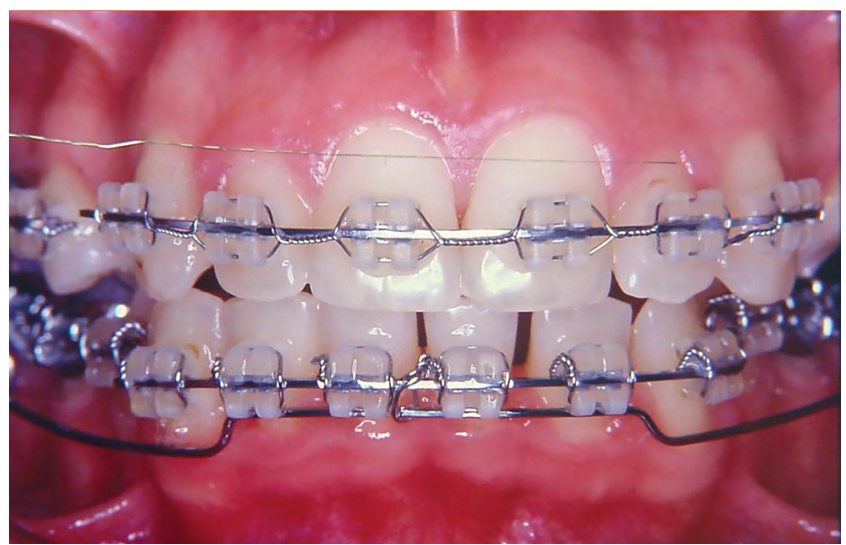

Figure 6 - A base archwire can be tied over the main archwire instead of being inserted to the brackets. In this case, the force system is determined and more predictable. 
produced at the molars contributes to the correction of the curve of Spee. The molar uprighting causes a change in the angle of entry of the main archwire on the tube and aids the leveling of the premolars and canines. As the leveling occurs, the alignment archwire, which was directed apically, approaches parallelism with the maxillary occlusal plane. Finally, occlusal pressure controls unwanted extrusive force on the molars and has no significant effects if the cantilever force stays low.

Clinicians can construct the cantilevers with $0.017 \times 0.025$-in or $0.019 \times 0.025$-in stainless steel wires with an open helix or with straight beta-titanium wires. The vertical force measured at the anterior engagement point should be around 80 grams-force. This produces an intrusive force anteriorly and an extrusive force posteriorly along with a crown-distal tipping of the molars with an intensity that is easily calculated. For example, if the distance between the molar tube and the engagement point of the cantilever is $25 \mathrm{~mm}$, the moment produced will equal 80 times $25 \mathrm{~mm}$, which totals 2000 gf.mm (Fig 9). This force system will achieve correction of a deep curve of Spee while alignment occurs, with clinically imperceptible side effects.

The relatively low intensity cantilever force and the occlusal forces offer an explanation for the lack of molar extrusion with consequent premature contacts or opening of the mandibular plane. The root morphology of the mandibular molars places the axis of resistance very close to the line of action of the vertical force, which prevents significant lingual tipping (Fig 9). These limited side effects justify not using a lingual arch to control side effects. The advantages of the EVC makes it simple to use on a daily basis and does not require molar bands and/or lingual arches. The technique requires only double tubes for the mandibular molars.
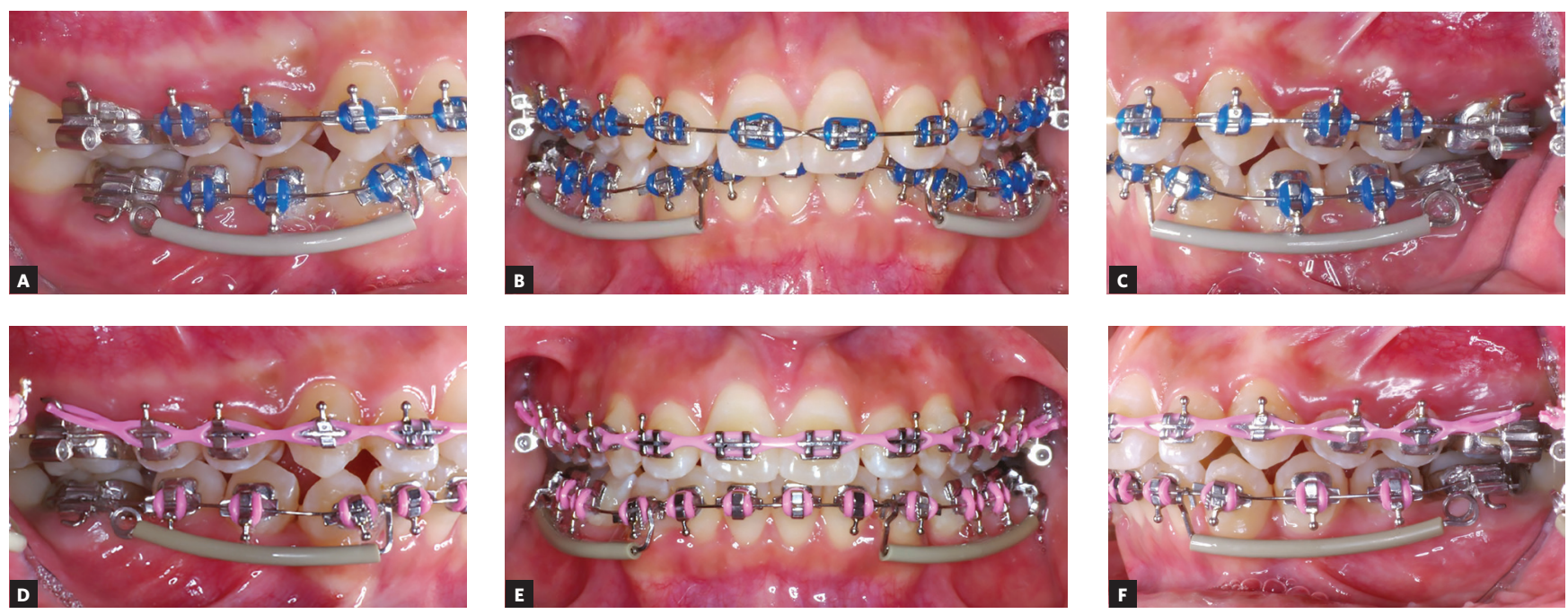

Figure 7 - Correction of a deep curve of Spee during alignment using the early vertical correction (EVC). A, B, C) The flattening of the curve of Spee is managed with two $0.017 \times 0.025$-in stainless steel cantilevers while the flexible 0.014-in NiTi archwire allows proper alignment. D, E, F) Two-month progress photographs of the improved vertical relationship. The correction of the curve of Spee occurred faster than the alignment of the teeth, which is still incomplete. The absence of change in the AP relationship points towards no extrusion of the molars. 


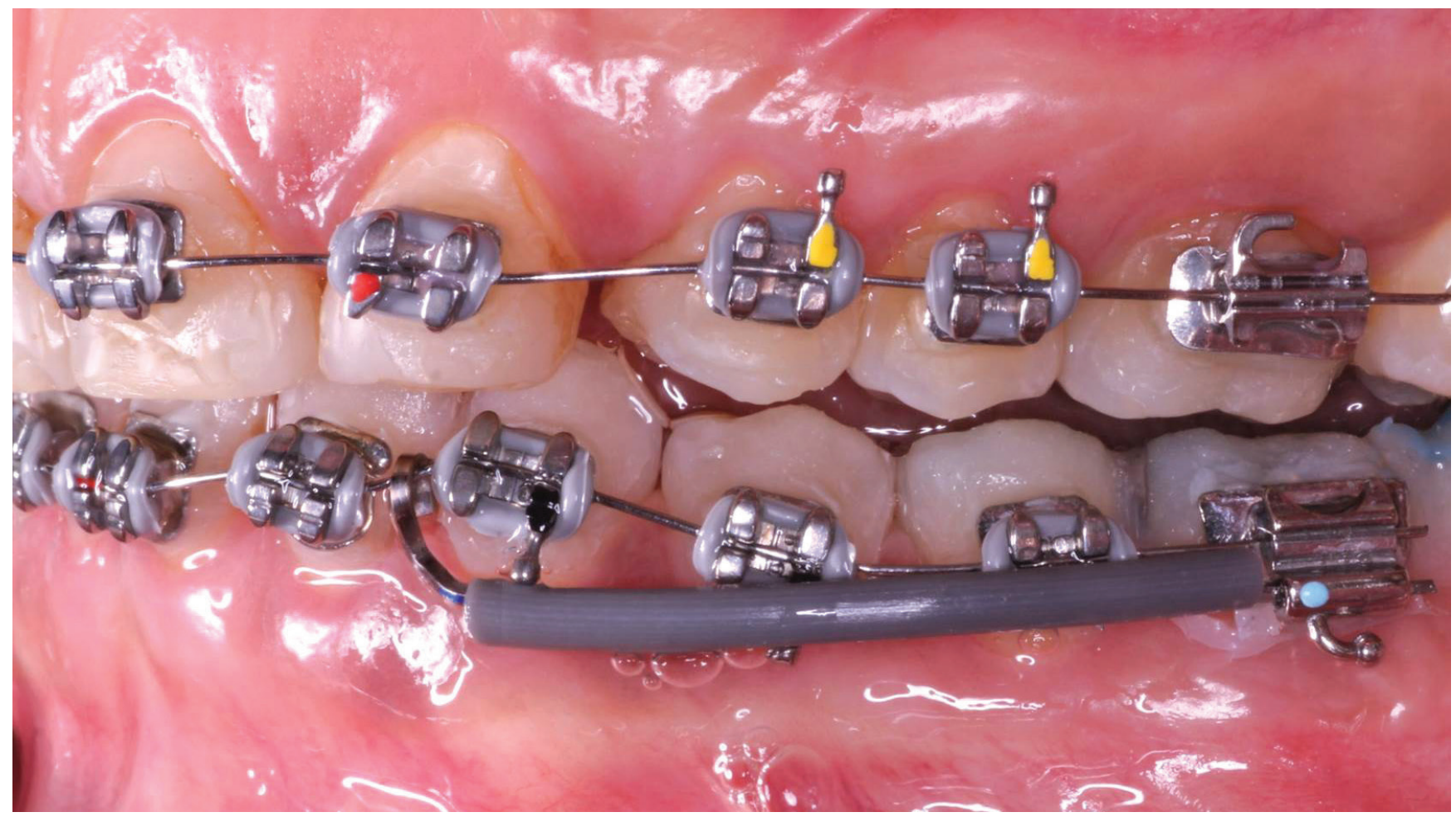

Figure 8 - Clinical application of the EVC with 0.017 x 0.025-in beta-titanium cantilever over a 0.014-in NiTi archwire. The cantilever causes an apical deflection of the archwire mesial to the canine bracket, minimizing extrusion of the incisors. Obs.: The upsidedown bracket bonded to maxillary canine substituting the lateral incisor aims to reverse the direction of its torque.

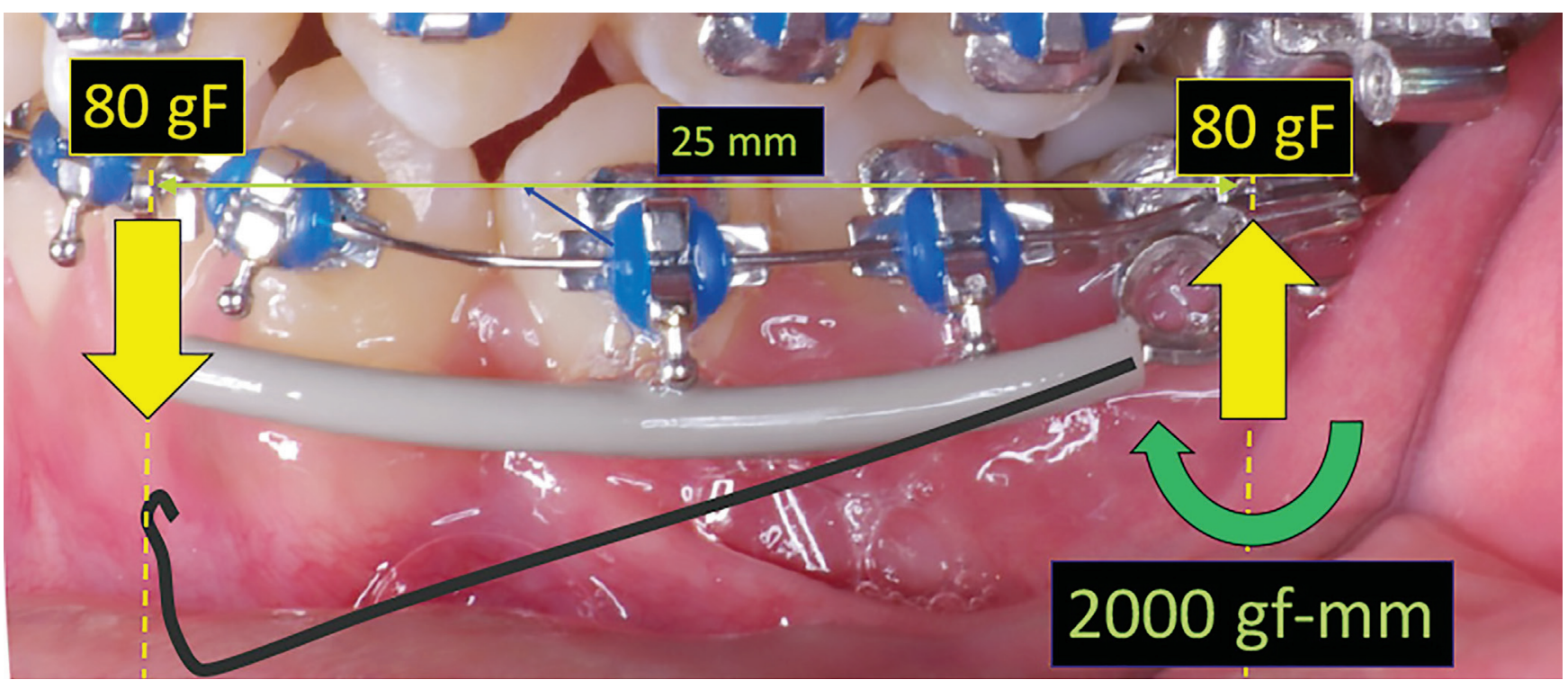

Figure 9 - Force diagram of the EVC cantilever with its preactivated shape shown in gray. It produces an intrusive force of 80 gf anteriorly, an extrusive force of $80 \mathrm{gf}$ posteriorly and a crown-distal tipping tendency of $2000 \mathrm{gF} . \mathrm{mm}$ in the molars. 


\section{CONCLUSION}

A typical orthodontic rationale waits for alignment correction before leveling the curve of Spee. Clinicians can combine these two features with an Early Vertical Correction (EVC) protocol that offers efficiency with excellent treatment outcomes.

\section{Acknowledgement}

The author would like to thank the contribution of Dr. Larry White in the preparation of the English version of this manuscript.
1. Segal GR, Schiffman PH, Tuncay OC. Meta analysis of the treatment-related factors of external apical root resorption. Orthod Craniofac Res. 2004 May; $7(2): 71-8$

2. Tsichlaki A, Chin SY, Pandis N, Fleming PS. How long does treatment with fixed orthodontic appliances last? A systematic review. Am J Orthod Dentofacial Orthop. 2016 Mar;149(3):308-18.

3. Skidmore KJ, Brook KJ, Thomson WM, Harding WJ. Factors influencing treatment time in orthodontic patients. Am J Orthod Dentofacial Orthop. 2006 Feb;129(2):230-8

4. Melo AC, Carneiro LO, Pontes LF, Cecim RL, de Mattos JN, Normando D. Factors related to orthodontic treatment time in adult patients. Dental Press J Orthod. 2013:18(5):59-63.

5. Mavreas D, Athanasiou AE. Factors affecting the duration of orthodontic treatment: a systematic review. Eur J Orthod. 2008 Aug;30(4):386-95

6. Chen SS, Greenlee GM, Kim JE, Smith CL, Huang GJ. Systematic review of self-ligating brackets. Am J Orthod Dentofacial Orthop. 2010 June:137(6):726.e1-726.e18; discussion 726-7.

7. Papageorgiou SN, Konstantinidis I, Papadopoulou K, Jager A, Bourauel C. Clinical effects of pre-adjusted edgewise orthodontic brackets: a systematic review and meta-analysis. Eur J Orthod. 2014 June:36(3):350-63
8. Janson G, Barros SE, Freitas MR, Henriques JF, Pinzan A. Class II treatment efficiency in maxillary premolar extraction and nonextraction protocols. Am J Orthod Dentofacial Orthop. 2007 Oct;132(4):490-8.

9. Dimberg L, Lennartsson B, Arnrup K, Bondemark L. Prevalence and change of malocclusions from primary to early permanent dentition: a longitudinal study. Angle Orthod. 2015 Sept;85(5):728-34

10. Angle EH. Some new forms of orthodontic mechanism, and the reasons for their introduction. Dent . 1928:70:1143-58

11. Fleming PS, Lee RT, McDonald T, Pandis N, Johal A. The timing of significant arch dimensional changes with fixed orthodontic appliances: data from a multicenter randomised controlled trial. J Dent. 2014 Jan;42(1):1-6.

12. Berendt CJ, Nelseon G, Meyer M. Orthodontic Archwire. In: Patent US editor. Carlsbad: Lancer Pacific; 1989

13. Isaacson RJ, Rebellato J. Two-couple orthodontic appliance systems: torquing arches. Semin Orthod. 1995 Mar;1(1):31-6. 